\title{
Guidelines for Selection of Appropriate Seismic Countermeasures for Existing Mountain Tunnels in Poor Geological Conditions
}

\author{
Kazuhide YASHIRO, Dr. Eng. \\ Keisuke SHIMAMOTO \\ Senior Researcher, \\ Researcher, \\ Laboratory Head, \\ Tunnel Engineering Laboratory, Structure Technology Division

\begin{abstract}
In this study, the authors performed model tests and numerical analyses to clarify the quantitative effect of seismic countermeasures for existing mountain tunnels in poor geological conditions. It has become apparent that inner reinforcement can control the initiation of cracks and prevent spalling; backfill grouting can improve deformation performance of the tunnel and control compressive failure in arch crowns; and rock bolts can control heaving of the roadbed. Even though there are many restrictions associated with construction of inverts, it has become apparent that inverts are a fundamental countermeasure to control tunnel deformation and heaving of the roadbed.
\end{abstract}

Yoshiyuki KOJIMA, Dr. Eng.

Keywords: tunnel, poor geological conditions, seismic damage, countermeasures, model test, numerical analysis

\section{Introduction}

Although mountain tunnels are assumed to be earthquake-resistant structures, previous studies [1,2] have shown that they may sometimes suffer damage such as cracking and compressive failure (i.e., spalling caused by bending compression failure) depending on earthquake magnitude and distance from the seismic source. The authors previously carried out case studies to examine seismic damage to mountain tunnels and researched its mechanisms $[3,4]$ with a view to alleviating such damage. Although various seismic countermeasures (Fig. 1, such as backfill grouting, rock bolts, inner reinforcement and inverts) for existing mountain tunnels have recently been implemented, their quantitative effects are still largely unknown. This paper shows the results of model tests and numerical analyses that were conducted to examine the effectiveness of these countermeasures and to draw up a guideline for selecting appropriate seismic countermeasures for existing mountain tunnels in ground with poor geological conditions.

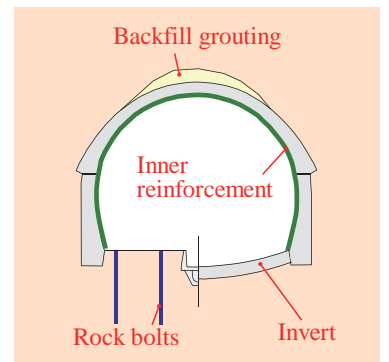

Fig. 1 Various seismic countermeasures for existing mountain tunnels

\section{Types of damage investigated in this study}

As previously reported [2], aside from landslides, earthquake damage to mountain tunnels can be broadly classified into the three types shown in Fig. 2: Type I dam-

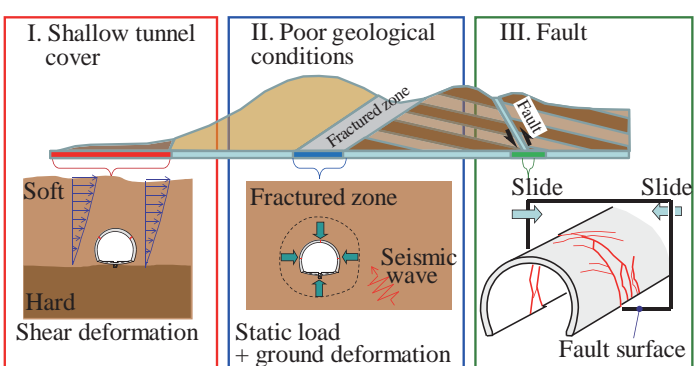

Fig. 2 Modes of earthquake damage to mountain tunnels

age in sections with shallow covering, Type II damage in ground with poor geological conditions and Type III damage caused by fault displacement. Among these, many cases of Type II damage have been reported in recent years, but the mechanisms involved have not been thoroughly clarified. In addition, this type of damage tends to be more severe $[3,4]$. This study, therefore investigates Type II damage in ground with poor geological conditions.

\section{Model tests on countermeasure effectiveness}

\subsection{Test method}

Firstly, the effectiveness of countermeasures was assessed by model testing. It is considered that Type II damage in ground with poor geological conditions is caused by the displacement of ground resulting from seismic movement or initial loading such as loosening of the ground load and plastic ground pressure. For this reason, we used a model tunnel loading test apparatus (Fig. 3 ) in our experiment. A model tunnel was buried in some ground, also serving as a model, and testing was performed by inducing displacement of the tunnel via the ground using jacks. In the case of Type II damage in the ground with poor geological conditions, the pattern of damage to the tunnel varies depending on the direction 


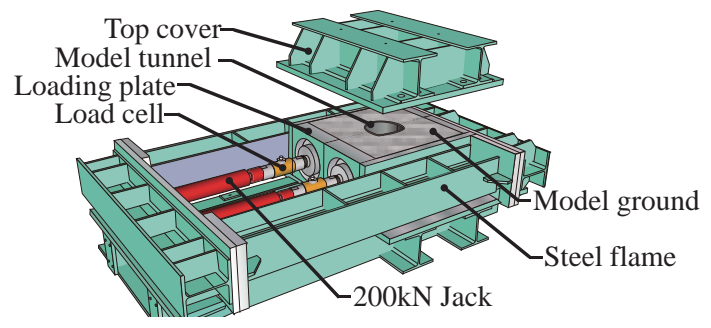

Fig. 3 Model tunnel loading test apparatus

and range of displacement. Tests however were performed by applying a uniform horizontal load in order to focus on the damage pattern associated with horizontal contraction of the inner section of the tunnel over a relatively long distance along its longitudinal axis, thus causing compressive failure on the arch crown. This approach was selected given the common nature of this type of damage pattern, and the time-consuming recovery required in the event of degradation of the arch crown.

Figure 4 shows the dimensions of the soil tank and the model tunnel. The model tunnel is made of mortar to a scale of 1/50 with a standard Shinkansen-line tunnel cross section. Two types were constructed: one with an invert and the other without. The compressive strength of the mortar was about $26 \mathrm{MPa}$. On the other hand, mortar of low cement mixing content with a compressive strength of about $0.5 \mathrm{MPa}$ was used for the ground since the strength of the ground in poor geological conditions is generally low, and is assumed to be not greater than that of soft rocks.

Loading was applied through displacement control up to $18 \mathrm{~mm}$ of $D$, the displacement of the loading plate (ground strain $D / L=3 \%$; refer to Fig. 4 for the definition). During the test, the jack load, the displacement of the loading plate, the displacements of the tunnel's inner surface and the displacement of the tunnel base were measured. Observations were made of the cracks on the inner surface of the lining through an observation window and with a webcam.

The countermeasures investigated in this trial include backfill grouting (hereafter referred to as "grouting"), roadbed rock bolts (hereafter referred to as "rock bolts"), inner reinforcement and inverts. For simplification, grouting is simulated by ensuring there is no void above the lining of the arch section of the tunnel, which is not a true representation of the actual countermeasure. Rock bolts were simulated using aluminum bars. In order to provide friction between them and the ground, these bars were covered with sand after applying glue to them. Aramid was selected as the inner reinforcement material. One layer of aramid sheet with a unit weight of $40 \mathrm{~g} / \mathrm{m}^{2}$ was
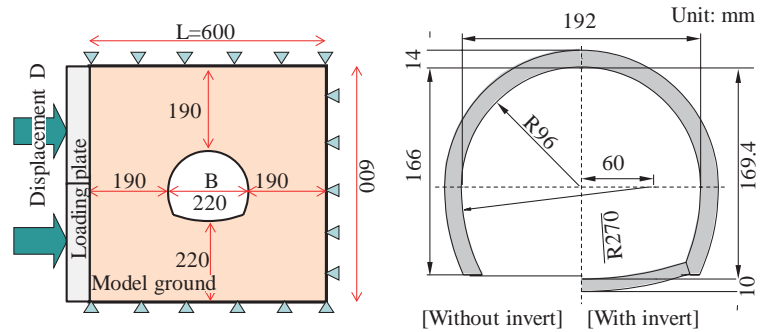

Fig. 4 Dimensions of the soil tank and the model tunnel
Table 1 Parameters of the countermeasures

\begin{tabular}{|l||l|l|}
\hline Countermeasure & Material & Remarks \\
\hline \hline $\begin{array}{l}\text { Backfill } \\
\text { grouting }\end{array}$ & Mortar & $\begin{array}{l}\text { Represented by not } \\
\text { providing a void } \\
\text { above the lining }\end{array}$ \\
\hline Rock bolts & $\begin{array}{l}\text { Aluminum bar } \\
\text { 6 bolts/section } \\
\text { Longitudinal direction: } \\
\text { 40mm spacing }\end{array}$ & $\begin{array}{l}\varphi=3 \mathrm{~mm} \\
L=100 \mathrm{~mm}\end{array}$ \\
\hline $\begin{array}{l}\text { Inner } \\
\text { reinforcement }\end{array}$ & Aramid sheet & $40 \mathrm{~g} / \mathrm{m}^{2}$ (One layer) \\
\hline Invert & Mortar & $t=10 \mathrm{~mm}$ \\
\hline
\end{tabular}

\begin{tabular}{|l|l|l|}
\hline $\begin{array}{l}\text { Case 1 } \\
\text { With void }\end{array}$ & $\begin{array}{l}\text { Case 2 } \\
\text { Backfill grouting }\end{array}$ & $\begin{array}{l}\text { Case 3 } \\
\text { Grouting + rock bolts }\end{array}$ \\
\hline \hline
\end{tabular}

Fig. 5 Test cases

bonded to the inner circumference of the tunnel with epoxy resin. Note that the rock bolts and inner reinforcement were modeled as being larger than their actual sizes so that their effect could be clearly verified. Table 1 shows the parameters of the countermeasures and Fig. 5 illustrates the test cases.

\subsection{Test results}

The deformation of the tunnel was reviewed, with focus on ground strain $D / L$, the tunnel deformation ratio $\delta / B$ and the vertical displacement of the tunnel base $u$. Figure 6 shows the relationships among $D / L, \delta / B$ and $u$. The results of Case 4 (grouting + inner reinforcement) are not shown here since they displayed almost the same tendency as those of Case 2 (grouting).

First, regarding $\delta / B$, the horizontal inner section of tunnel tended to contract with increased load in all cases, though the level of contraction decreased as countermeasures were introduced starting with Case 2 (grouting) to

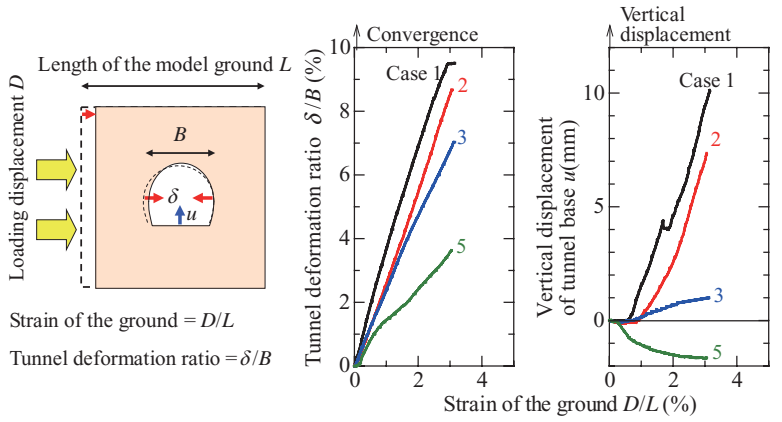

Fig. 6 Relationships among $D / L, \delta / B$ and $u$ 
Case 3 (grouting + rock bolts) and then to Case 5 (grouting + invert). In Case 5, it is considered that deformation was controlled by the increased rigidity of the tunnel which was achieved by closing the cross section of the tunnel in the shape of a ring with the invert, thus creating an arch action. In Case 3, the level of contraction in the horizontal inner section of tunnel was also mitigated, though by a smaller amount than in Case 5. This is also attributed to the increased rigidity of the tunnel as a whole because the ground around the tunnel was reinforced in the shape of a ring by reinforcing the tunnel bottom section with rock bolts.

In Cases 1 to $3, u$ is positive, meaning that heaving occurs as the $D / L$ value increases. In Cases 1 and 2 , in particular, $u$ increased sharply when $D / L$ was about $1 \%$, causing the tunnel base to heave. Track bed heaving was restrained however in Cases 3 and 5.

The above results indicate that grouting alone has little effect on controlling tunnel deformations such as the contraction of the horizontal inner section of tunnel and heaving of the tunnel base and that the effect of deformation control becomes apparent only by implementing countermeasures such as rock bolts and inverts. Grouting is generally considered to be a basic countermeasure against failures caused by external forces. However, the tests conducted in this study assumed an absence of inverts in the tunnels as a basic case, and so it could not be shown that grouting was effective in deformation control. Nonetheless its effect on preventing compressive failure of the lining was confirmed, as shown in Fig. 8 (described later).

Figure 7 shows the failure patterns in the lining (inner surface) at the end of the loading process. These failures mainly consist of tensile cracks on sidewalls since the load was applied in the horizontal direction. The failures progressed to the arch crowns except in Cases 2 and 4. In Case 1, in particular, compressive failure appeared at the arch crown early in the loading process, and finally, a large compressive failure occurred that extended along the tunnel's longitudinal axis. Cracks on the sidewall were also accompanied by horizontal slide. Thus, the failure level was the highest in this case. Though grouting helped prevent the initiation of large compressive failure at the arch crown and inner reinforcement controlled tensile cracking, the other countermeasures had no significant impact on the inception of crack and compressive failure patterns.

The effects of each countermeasure are summarized in Fig. 8. This diagram shows the $D / L$ values at the time of the first appearance of lining failure (cracking and

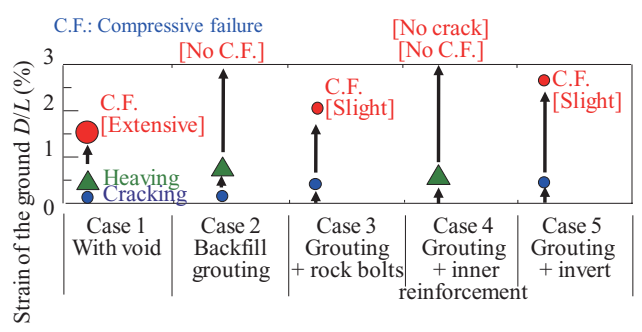

Fig. 8 Effects of each countermeasure

compressive failure) and tunnel base heaving. Cracking occurred in all cases except in Case 4 (grouting + inner reinforcement), and the strain $D / L$ at the time of appearance of cracks was about $0.2 \%$ to $0.5 \%$. Heaving of the tunnel base occurred when the strain $D / L$ was about $0.5 \%$ to $1 \%$ in Cases 1,2 and 4 where neither rock bolts nor invert were implemented. Compressive failure occurred when $D / L$ was around $1.5 \%$ in Case 1 where in the presence of a void above the lining, but it did not occur until $D / L$ was about $2 \%$ to $2.5 \%$ in Cases 3 and 5 , and even at $D / L=3 \%$ in Cases 2 and 4 .

The above facts indicate that compressive failure can be controlled by grouting; heaving of the tunnel base, by rock bolts; cracking, by inner reinforcement; and tunnel deformations (such as contraction of the horizontal inner section of tunnel and heaving of the tunnel base), by inverts.

It should be noted, however, that in these tests the scales of the countermeasures using rock bolts and inner reinforcement were larger relative to the model tunnel size due to the constraints of model testing, meaning that the effects of these countermeasures were magnified compared to reality.

\section{Numerical analyses of the effects of countermeasures}

\subsection{Modeling method for plain concrete}

Next, countermeasures were assessed by numerical analysis, assuming their application to actual tunnels.

Analysis of mountain tunnel linings made of plain concrete, requires use of a method capable of modeling their behavior after reaching their tensile or compressive strength limits, in order to track deformation and destruction in detail. A model [5] was therefore employed that takes into account the softening process of concrete after tensile destruction and its softening behavior after reaching the compressive strength.

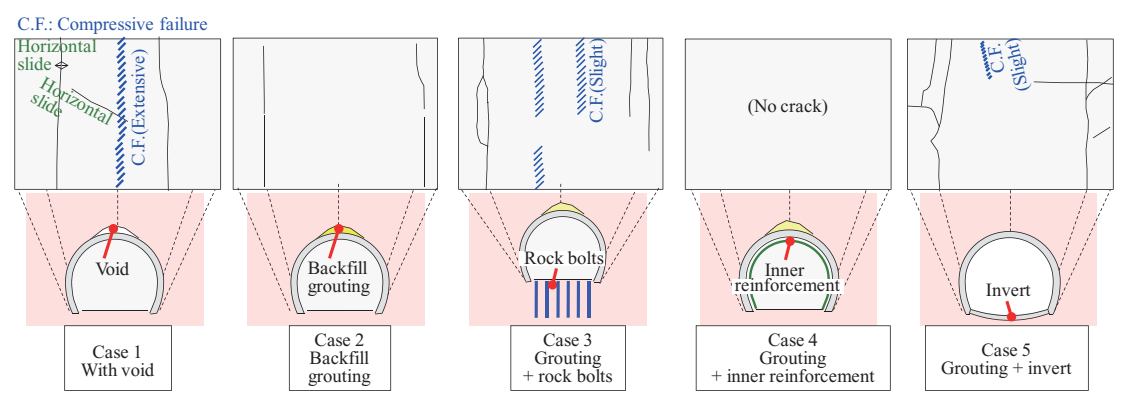

Fig. 7 Lining failure patterns 


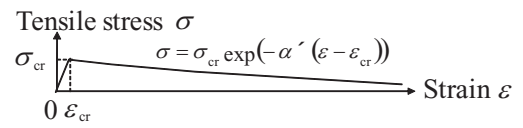

Fig. 9 Softening of concrete after tensile failure

Plain concrete does not contain reinforcement bars so deep and wide cracks can occur, therefore it is necessary to represent cracks in the analysis. The model employed in this study represents concrete with the assumption that it will soften exponentially after reaching the tensile strength, as shown in Fig. 9, where $\sigma_{\text {cr }}$ is the stress at the time when cracking occurs; $\varepsilon_{\mathrm{cr}}$, the strain at the time when cracking occurs; and $\alpha$, the coefficient of tensile softening. For $\alpha$, the commonly used value of 200 [5] was adopted. It was also assumed that the direction of cracking rotates if the direction of the main stress rotates when a load is applied.

In a typical FEM analysis, stress in concrete is no longer considered after reaching the compressive strength, and analyses usually ends at this stage. In practice, however, considerable stress is retained even after the compressive strength is reached, as described in the reference [5]. Therefore, we modeled concrete that had reached the compressive strength assuming that softening occurs exponentially, as shown in Fig. 10, where $\sigma_{\mathrm{cr}}{ }^{\prime}$ is the compressive strength; $\varepsilon_{\mathrm{s}}^{\prime}$, the strain when the softening process starts; and $\beta$, the coefficient of compressive softening. A value of 260 was adopted for $\beta$ which represents the speed of the softening process, and 2,500 $\mu$ was adopted for the equivalent plastic strain $\varepsilon_{\mathrm{s}}{ }^{\prime}$ at the start of the softening process [5].

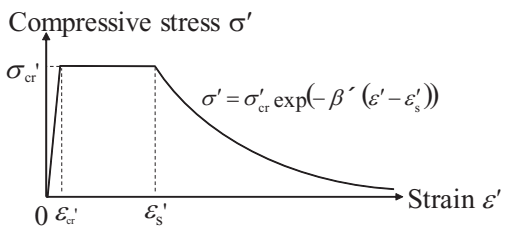

Fig. 10 Softening of concrete after compressive failure

\subsection{Analysis conditions}

Figure 11 (a) shows the analysis model. This model represents a mountain tunnel in ground with poor geological conditions. The modeled area dimensions are set to 50 meters in the horizontal direction and 100 meters in the vertical direction to ensure that the effect of the tunnel does not go beyond the model perimeter. In order to reduce the analysis time, a half model was employed using the principle of symmetry. Since tunnel deformation in the ground with poor geological conditions tends to occur in such a way that the horizontal inner section of tunnel contracts, strain was applied in the horizontal direction in our model, and displacement to the right was induced up to a $D / L$ value of $1.2 \%$ (refer to Fig. 11 (a) for the definitions of $D$ and $L$ ) on the left boundary. Figure 11 (b) shows the cross section of the tunnel used in the analysis and a schematic drawing of countermeasures. We selected a tunnel with a standard Shinkansen-line tunnel cross section constructed according to conventional methods, and assumed two types of tunnel: with and with-
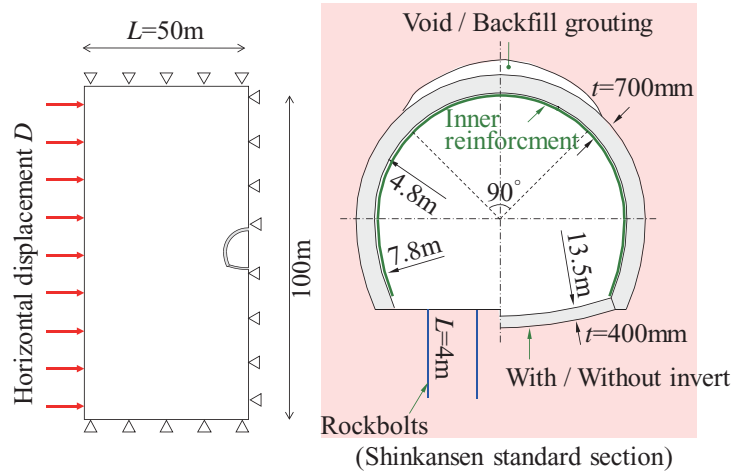

(a) Analysis model

(b) Cross section of the tunnel used in the analysis and schematic drawing of countermeasures

Fig. 11 Analysis model

out invert. Construction joints between the arch and sidewalls were not factored into the model.

Table 2 summarizes the model properties. This analysis adopted soft rock for the ground. More specifically, the selected soft rock was of low-strength and consisted of an elastic-perfectly plastic solid that follows the MohrCoulomb criterion with a deformation modulus of $30 \mathrm{MPa}$ and a cohesion of $0.15 \mathrm{MPa}$ (equivalent to compressive strength of $0.3 \mathrm{MPa}$ ). For the lining, standard concrete was utilized with a strength value of $24 \mathrm{MPa}$. Table 3 shows the cases analyzed. In line with the model tests outlined in Section 3, five cases were set up. For Case 4

Table 2 Properties of the analytical model

\begin{tabular}{|c|c|c|c|c|}
\hline \multicolumn{3}{|c|}{ Parameters } & Input value & Remarks \\
\hline \multirow{7}{*}{ 菍. } & \multicolumn{2}{|c|}{ Unit weight $\gamma_{t}$} & $23.5 \mathrm{kN} / \mathrm{m}^{3}$ & From reference [7] \\
\hline & \multirow{3}{*}{ 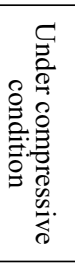 } & $\begin{array}{l}\text { Compressive } \\
\text { strength } \sigma_{\mathrm{cr}}\end{array}$ & $24 \mathrm{MPa}$ & $=f_{\text {ck }}^{\prime}$, standard value \\
\hline & & $\begin{array}{l}\text { Young's } \\
\text { modulus } E_{\mathrm{c}}\end{array}$ & $2.5 \times 10^{4} \mathrm{MPa}$ & From reference [7] \\
\hline & & $\begin{array}{l}\text { Strain at } \\
\text { cracking occurs } \\
\varepsilon_{\mathrm{cr}}^{\prime}\end{array}$ & $960 \mu$ & $=\sigma_{\mathrm{cr}}^{\prime} / E_{\mathrm{c}}$ \\
\hline & \multirow{3}{*}{ 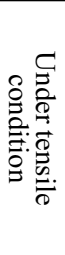 } & $\begin{array}{l}\text { Tensile strength } \\
\sigma_{\mathrm{cr}}\end{array}$ & $1.9 \mathrm{MPa}$ & $=f_{\mathrm{t}}=0.23 \times f_{\mathrm{ck}^{2 / 3}}^{2 / 3}$ \\
\hline & & $\begin{array}{l}\text { Young's } \\
\text { modulus } E_{\mathrm{t}}\end{array}$ & $2.5 \times 10^{4} \mathrm{MPa}$ & $=E_{\mathrm{c}}$ \\
\hline & & $\begin{array}{l}\text { Strain at } \\
\text { softening } \\
\text { occurs } \varepsilon_{\mathrm{cr}}\end{array}$ & $76 \mu$ & $=\sigma_{\mathrm{cr}} / E_{\mathrm{c}}$ \\
\hline \multirow{5}{*}{ 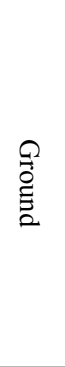 } & \multicolumn{2}{|c|}{ Non-liner model } & $\begin{array}{l}\text { Elastic - } \\
\text { perfectly } \\
\text { plastic }\end{array}$ & $\begin{array}{l}\text { Mohr-Coulomb } \\
\text { criterion }\end{array}$ \\
\hline & \multicolumn{2}{|c|}{$\begin{array}{l}\text { Deformation modulus } \\
E_{\mathrm{c}}\end{array}$} & $30 \mathrm{MPa}$ & $\begin{array}{l}\text { Assumed to be soft } \\
\text { rock }\end{array}$ \\
\hline & \multicolumn{2}{|c|}{$\begin{array}{l}\text { Compressive strength } \\
q_{\mathrm{u}}\end{array}$} & $0.5 \mathrm{MPa}$ & $\begin{array}{l}\text { Assumed to be soft } \\
\text { rock }\end{array}$ \\
\hline & \multicolumn{2}{|c|}{ Cohesion $c$} & $0.15 \mathrm{MPa}$ & $c=q_{\mathrm{u}} / 2$ \\
\hline & \multicolumn{2}{|c|}{ Poisson ratio } & 0.25 & $\begin{array}{l}\text { Assumed to be soft } \\
\text { rock }\end{array}$ \\
\hline \multirow{2}{*}{ 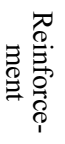 } & \multicolumn{2}{|c|}{ Young's modulus $E$} & $\begin{array}{l}1.56 \times 10^{5} \\
\mathrm{MPa}\end{array}$ & Carbon fiber plate \\
\hline & \multicolumn{2}{|c|}{ Dimension } & $100 \mathrm{~mm} \times 2 \mathrm{~mm}$ & $\begin{array}{l}\text { Longitudinal intervals: } \\
1 \mathrm{~m}\end{array}$ \\
\hline
\end{tabular}


Table 3 Cases and their conditions

\begin{tabular}{|l||l|l|}
\hline No. & Condition & Remarks \\
\hline \hline Case 1 & With void & Range of 90 degree of arch \\
\hline Case 2 & Backfill grouting & - \\
\hline Case 3 & Grouting + rock bolts & $\begin{array}{l}\mathrm{D} 25, L=4 \mathrm{~m}, 4 \text { bolts } / \text { section, } \\
\text { longitudinal intervals: } 1 \mathrm{~m}\end{array}$ \\
\hline Case 4 & $\begin{array}{l}\text { Grouting + } \\
\text { inner reinforcement }\end{array}$ & Carbon fiber plate \\
\hline Case 5 & Grouting + invert & Thickness of invert $t=400 \mathrm{~mm}$ \\
\hline
\end{tabular}

(grouting + inner reinforcement), however, we employed the carbon fiber plate bonding method [6] which has a greater reinforcing effect than the reinforcement sheet bonding method.

In this analysis, the sections where the equivalent plastic strain $\varepsilon_{\text {eq }}$ given in (1) exceeds $1 \%$ are assumed to be equivalent to the areas where compressive failure occurs.

$$
\varepsilon_{\mathrm{eq}}=\frac{\sqrt{2}}{3} \sqrt{\left(\varepsilon_{1}^{\mathrm{p}}-\varepsilon_{2}^{\mathrm{p}}\right)^{2}+\left(\varepsilon_{2}^{\mathrm{p}}-\varepsilon_{3}^{\mathrm{p}}\right)^{2}+\left(\varepsilon_{3}^{\mathrm{p}}-\varepsilon_{1}^{\mathrm{p}}\right)^{2}}
$$

$\left(\varepsilon_{1}, \varepsilon_{2}, \varepsilon_{3}:\right.$ Maximum, intermediate, minimum main strain; p: plastic component, with positive value for extension)

As for the equivalent plastic strain value of $1 \%$, its validity has been partially verified in previous simulation analyses [5] of the model tests, though it should be confirmed by testing.

\subsection{Analysis results}

Figure 12 shows the deformation modes of the tunnel for a ground strain $D / L=1 \%$ in Case 1 (with void), Case 2 (grouting), Case 3 (grouting + rock bolts) and Case 5 (grouting + invert). Figure 13 shows the relationships between $D / L$, and each of the tunnel deformation ratios (horizontal direction) $\delta_{\mathrm{h}} / B$, (vertical direction) $\delta_{\mathrm{v}} / H$ and the vertical displacement of the tunnel base $u$.

Because displacement is evenly applied in the horizontal direction, the horizontal convergence in the tunnel indicates contraction. In Case 1, the lining on the arch crown was displaced toward the void above the lining, and a sharp increase in the vertical displacement of the tunnel base (heaving of the tunnel base) occurred at a $D / L$ value of about $0.5 \%$. In Case 2 , the behavior at the arch crown described above was controlled by grouting, but the effect of controlling the contraction of the horizontal inner section of tunnel was not apparent. Naturally, in this case there was no effect on controlling the vertical displacement of the tunnel base. In Case 3 , a sharp increase in the vertical displacement of the tunnel

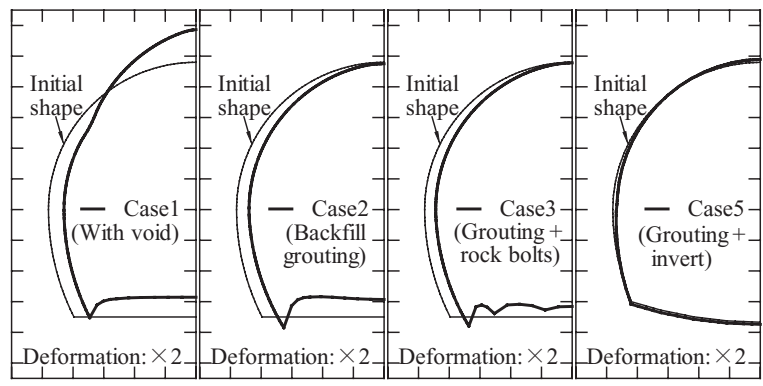

Fig. 12 Deformation modes of the tunnel at $D / L=1 \%$

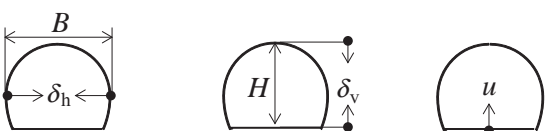

Tunnel deformation ratio Tunnel deformation ratio Vertical displacement (Horizontal dir.) $\delta_{\mathrm{h}} / B$ (Vertical dir.) $\delta_{\mathrm{v}} / H \quad$ of tunnel base $u$

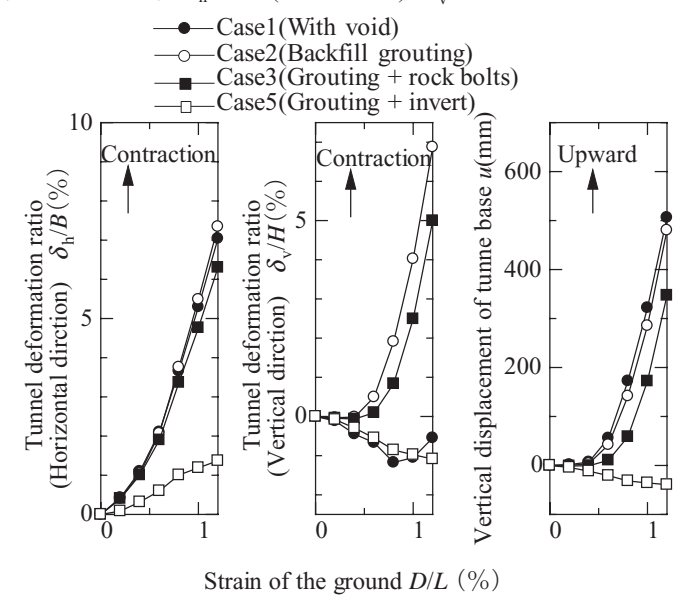

Fig. $13 \begin{aligned} & \text { Relationships between } D / L \text {, and } \delta_{\mathrm{h}} / B, \delta_{\mathrm{v}} / H \text { and } u \\ & \text { respectively }\end{aligned}$

base (heaving of the tunnel base) was controlled to some extent by rock bolts. On the other hand, there was not apparent control of contraction of the horizontal inner section of the tunnel. In Case 5, both the contraction of the horizontal inner section and a sharp increase in the vertical displacement of the tunnel base (heaving of the tunnel base) were controlled.

Furthermore, Case 4 (grouting + inner reinforcement) exhibited almost the same deformation pattern as that of Case 2. This is attributable to the fact that a significant tensile strain did not occur on the inside of the spring line section (hereafter referred to as "SL section") where inner reinforcement is effective, as shown in Fig. 14 (described later), and that the reinforced area in our model was too small to increase the rigidity of the tunnel structure as a whole even though its modulus of elasticity was 10 times that of concrete.

Figure 14 shows the distribution of equivalent plastic strain of the lining for ground strain $D / L=1 \%$ in Case 1 (with void), Case 2 (grouting), Case 4 (grouting + inner

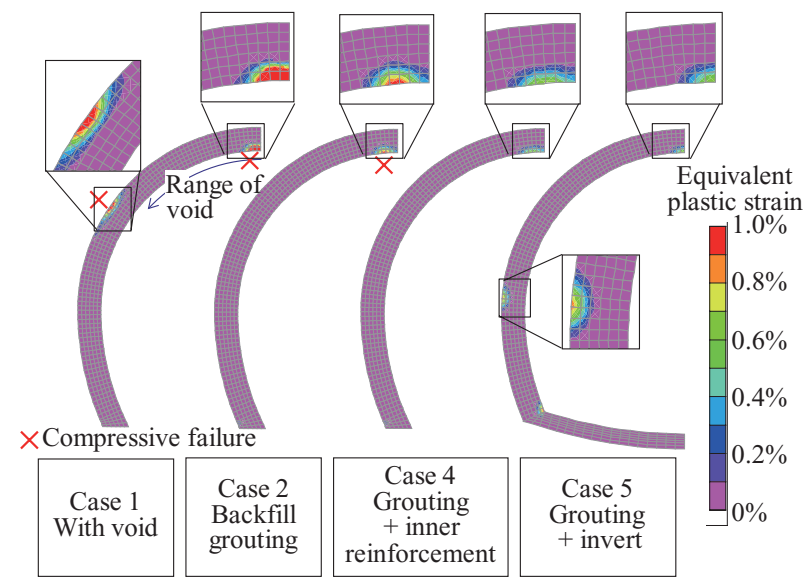

Fig. 14 Distribution of equivalent plastic strain of the lining for ground strain $D / L=1 \%$ 
reinforcement) and Case 5 (grouting + invert). Since the focus was on compressive failure, only the strain on the compressed side is shown here. Case 3 (rock bolts) displayed almost the same strain pattern as that in Case 2.

In Case 1, places with high strain are observed at the arch shoulder and arch crown, resulting in compressive failure in these locations. It is considered that the highstrain point at the arch crown was produced by the increased amount of bending because of the lack of subgrade reaction due to the existence of a void. At the arch shoulder where there is a change in boundary conditions given its position on the border between an area contacting the ground and an area with a void, it is possible to assume that the high-strain occurring at the shoulder was produced by the increased amount of bending. In Case 2, the overall level of strain was considerably smaller than that in Case 1. Compressive failure at the shoulder has disappeared here, resulting in a mode where compressive failure finally occurs only at the arch crown. In Case 4, although the strain distribution pattern is similar to that of Case 2, the strain level is comparatively somewhat smaller. Compressive failure at the arch crown is observed at $D / L=1 \%$ in Case 2 , while it is not observed at the arch crown at $D / L=1 \%$ in Case 4 . In Case 5 , the overall distribution pattern of strain differs from those in Cases 2 and 4, and a high-strain point is observed in the SL section as well as at the arch crown. This result can be explained as follows: without an invert, the model acts as a cantilever beam and a large amount of bending occurs at the arch crown which corresponds to the fixed end of the beam, resulting in the concentration of destruction at that point. With an invert, on the other hand, the model acts as a double-end supported beam because the sidewalls are joined to the invert, and as a result, a large amount of bending occurs in the SL section which corresponds to the middle section of the beam.

Figure 15 compares the tunnel deformation ratio (horizontal direction) $\delta_{\mathrm{h}} / B$ and the vertical displacement of the tunnel base $u$ at $D / L=1 \%$ for the each test case assuming that in Case 1 these are 1 .

First, focusing on the effect of grouting, $\delta_{\mathrm{h}} / B$ in Case 2 is almost the same as that in Case 1, thus the effect of controlling the horizontal deformation of tunnel cannot be verified. With regard to the $u$ value (tunnel base heaving), Case 2 shows some improvement over Case 1, although it is still significant, as shown in Figs. 12 and 13 , indicating that grouting is not sufficient as a countermeasure.

Next, regarding the rock bolts, Case 3 shows an ef-

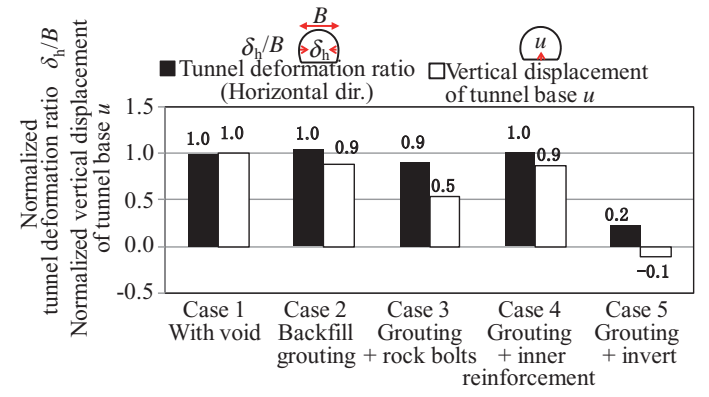

Fig. 15 Comparison of $\delta_{\mathrm{h}} / B$ and $u$ for the respective test cases at $D / L=1 \%$ fective reduction in the value of $u$ to about $50 \%$ of that in Case 1. But as $D / L$ increases, tunnel base heaving occurs as in Case 1 and $u$ increases at an accelerated rate, as shown in Fig. 13. This indicates that the length and the number of rock bolts installed are not sufficient to cope with the strength and deformation level of the ground. Therefore, the amount of reinforcement with rock bolts needs to be increased if large ground displacement is expected.

With regard to the inner reinforcement, both $\delta_{\mathrm{h}} / B$ and $u$ in Case 4 are the same as in Case 2, indicating that this measure has no effect on controlling the deformation of the tunnel in our analysis. Finally, regarding the invert, both $\delta_{\mathrm{h}} / B$ and $u$ were controlled to a greater degree than those in Case 1, verifying that this is an effective countermeasure for controlling deformation.

In summary, Fig. 16 shows the strain of the ground $D / L$ at the time of the initial appearance of a failure of the tunnel or lining (heaving of the tunnel base and compressive failure). It can be seen that compressive failure is suppressed by grouting and that some effect is expected from rock bolts and inner reinforcement. It is also apparent that heaving of the tunnel base can be suppressed by rock bolts and can be prevented by inverts.

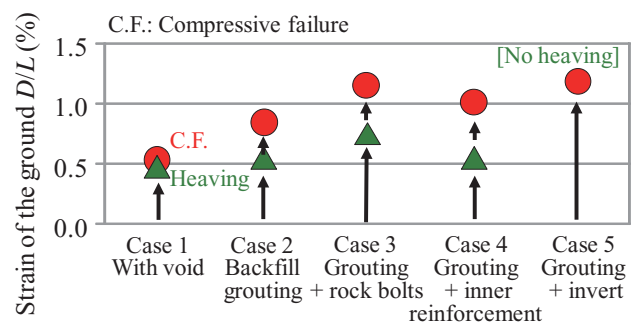

\section{Fig. $16 D / L$ at the time of the initial appearance of a failure of the tunnel or lining}

\section{Assessment of seismic countermeasures}

Based on the results of the above model tests and numerical analyses, the effectiveness of the countermeasures was assessed for each type of seismic damage to tunnels in ground with poor geological conditions, as shown in Table 4.

Inner reinforcement has little effect on controlling tunnel deformation but can prevent the initiation of tensile cracking; accordingly it can be applied as a viable countermeasure against cracking and spalling.

Backfill grouting can improve the deformation resistance performance of tunnels and prevent compressive failure at the arch crown, which significantly affects the safety of tunnels. This measure should be considered for tunnels with voids behind the arch crown that are located in ground with poor geological conditions, as external forces will act on such tunnels in the event of an earthquake. Examples of these poor geological conditions include fault or fractured zones, areas that have suffered a collapse in the past and sedimentary ground.

Roadbed rock bolts have little effect on controlling the contraction of horizontal inner section of tunnels but are effective for controlling heaving of the tunnel base. This measure should be considered for tunnels in ground 
Table 4 Effectiveness of respective countermeasures for each type of seismic damage to tunnels

\begin{tabular}{|l||c|c|c|c|}
\hline $\begin{array}{c}\text { Object for } \\
\text { application }\end{array}$ & $\begin{array}{l}\text { Control of } \\
\text { cracking and } \\
\text { spalling }\end{array}$ & $\begin{array}{l}\text { Improvement of } \\
\text { deformation } \\
\text { performance } \\
\text { (Control of } \\
\text { compressive failure) }\end{array}$ & $\begin{array}{l}\text { Control of } \\
\text { tunnel } \\
\text { deformation }\end{array}$ & $\begin{array}{l}\text { Control of } \\
\text { heaving of the } \\
\text { tunnel base }\end{array}$ \\
\hline \hline $\begin{array}{l}\text { Inner } \\
\text { reinforcement }\end{array}$ & $\bigcirc$ & $\triangle$ & - & - \\
\hline $\begin{array}{l}\text { Backfill } \\
\text { grouting }\end{array}$ & - & $\bigcirc$ & - & - \\
\hline $\begin{array}{l}\text { Roadbed } \\
\text { rock bolts }\end{array}$ & - & - & $\triangle$ & $\bigcirc$ \\
\hline Invert & - & - & $\bigcirc$ & $\bigcirc$ \\
\hline
\end{tabular}

that is susceptible to tunnel base heaving due to a low ground strength ratio, or those located in areas where tunnel base heaving has occurred in the past or is occurring now.

Although there are many restrictions on constructing inverts in existing tunnels, this measure is capable of controlling tunnel deformation and preventing tunnel base heaving.

\section{Conclusion}

This study focused on seismic countermeasures for existing mountain tunnels in ground with poor geological conditions, and showed the results of model tests and numerical analyses as well as offering guidelines for selecting appropriate seismic countermeasures based on these results.

\section{Acknowledgement}

This paper includes results from "Studies on the Mechanism of Seismic Damage and Improvement of the Earthquake Resistance of Mountain Tunnels," conducted jointly by Kyoto University, the Railway Technical Research Institute and the Japan Railway Construction, Transport and Technology Agency as part of the Program for Promoting Fundamental Transport Technology Research of the Japan Railway Construction, Transport and Technology Agency (JRTT).

\section{References}

[1] Yoshikawa, K., "Earthquake Disaster Survey on Railway Tunnels," Research Report of the Railway Technical Institute, No. 1123, Sept. 1979 (in Japanese).

[2] Asakura, T., Shiba, Y., Matsuoka, S., Oya, T., and Yashiro, K., "Damage to Mountain Tunnels by Earthquakes and Its Mechanism," Journals of the Japan Society of Civil Engineers, No. 659/III-52, pp. 27-38, Sept. 2000 (in Japanese).

[3] Yashiro, K., Kojima, Y., Fukazawa, N., Asakura, T., and Takemura, J., "Seismic Damage Mechanism of Mountain Tunnels in Poor Geological Conditions," Journals of the Japan Society of Civil Engineers, Ser. C, Vol. 65, No. 4, pp. 1045-1061, Dec. 2009 (in Japanese).

[4] Yashiro, K., Kojima, Y., Asakura, T., and Fukazawa, N., "Seismic Damage Mechanism and Assessment of Aseismic Performance of Mountain Tunnels for Railways," Report of the Railway Technical Research Institute, Vol. 23, No. 12, pp. 17-22, Dec. 2009 (in Japanese).

[5] Yashiro, K., Kojima, Y., Arai, Y., Okano, N., and Takemura, J., "A Study on Numerical Simulation Method for Plain Concrete Tunnel Lining Considering Softening Due to Compression Failure," Journals of the Japan Society of Civil Engineers, Ser. C, Vol. 65, No. 4, pp. 1024-1038, Dec. 2009 (in Japanese).

[6] Okano, N., Uemura, Y., Kojima, Y., Saito, J., and Asakura, T., "A Study on Effect on Internal Reinforcements of Mountain Tunnel lining by model tests," Journal of tunnel Engineering, Vol. 19, pp. 69-76, Nov. 2009 (in Japanese).

[7] Ministry of Land, Infrastructure, Transport and Tourism (supervisor), Railway Technical Research Institute (editor), Design Standards for Railway Structures and Commentary [Concrete Structures], Maruzen Company, Limited, Tokyo, Japan, Apr. 2004 (in Japanese). 